\title{
Assessment of hospitalizations of patients after intoxication with organophosphates used in agriculture
}

\author{
Anna Katarzyna Orzeł ${ }^{1, A, D \oplus}$, Wojciech Flieger ${ }^{1, B, D \oplus}$, Dominika Szlichta ${ }^{1, A, D \oplus}$,

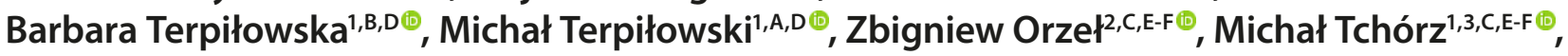

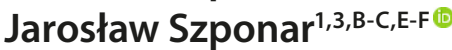 \\ ${ }^{1}$ Toxicology Clinic, Medical University, Lublin, Poland \\ ${ }^{2}$ Faculty of Human Sciences, University of Economics and Innovation, Lublin, Poland \\ ${ }^{3}$ Clinical Department of Toxicology and Cardiology, Stefan Wyszyński Regional Specialist Hospital, Lublin, Poland \\ A - Research concept and design, B - Collection and/or assembly of data, C - Data analysis and interpretation, \\ $D$ - Writing the article, $E$ - Critical revision of the article, $F$ - Final approval of the article
}

Orzeł AK, Flieger W, Szlichta D, Terpiłowska B, Terpiłowski M, Orzeł Z, Tchórz M, Szponar J. Assessment of hospitalizations of patients after intoxication with organophosphates used in agriculture Ann Agrc Environ Med. 2022; 29(1): 143-148. doi: 10.26444/aaem/145769

\begin{abstract}
Introduction. Clinical manifestation of organophosphates toxicity may be differentiate and include cholinergic toxidrome, intermediate syndrome, OP-induced delayed polyneuropathy to chronic OP-induced neuropsychiatric disorder (OPIDN). Patients symptoms, along with decrease in cholinesterase serum level, determines the possible diagnosis of organophosphate poisoning.

Objective. The aim of the study was to present the clinical manifestation and cholinesterase level changes in intoxication with organophosphorus compounds in patients.

Materials and method. A data base was created by analysis of the hospital documents of 34 patients hospitalized due to organophosphate intoxication. Statistical analysis involved frequency tables with percentage values, the application of non-parametric Chi-square test and parametric t-Student test (with homogeneity of variance Levine test). The level of static significance was set to $p=0.05$.

Results. In fatal hospitalizations (20.6\%), cholinesterase level was significantly lower (265.87 U/I) than in other patients (4254.78 U/l; $p<0.05)$. Similarly, levels of cholinesterase were decreased in group of patients with acute respiratory failure (999.79 U/I vs 4943.86 U/I in other patients; $p<0.05)$, patients with multi-organ dysfunction syndrome (244.13 U/I vs 4914.89 $\mathrm{U} / \mathrm{I}$ in other patients; $\mathrm{p}<0.05$ ) and those with cardiac arrest ( $547 \mathrm{U} / \mathrm{I}$ vs $4636.25 \mathrm{U} / \mathrm{I}$ in other patients). A statistically significant difference was also observed in cholinesterase level of patients who required mechanical ventilation (548.17 U/I vs 5219.71 $\mathrm{U} / \mathrm{l}$ in other group). The study revealed that $29.4 \%$ of poisonings were suicidal.

Conclusions. The management of a patient with organophosphate poisoning remains challenging and requires continuous control. A significant step in the diagnostic process is the assessment changes in both the clinical picture and cholinesterase level.
\end{abstract}

Key words

poisoning, organophosphates, intentional poisonins

\section{INTRODUCTION}

Organic phosphorus compounds (OPs) have been available and widely used in the agricultural industry and households for many decades. OPs belong to the group of cholinestaraseinhibiting pesticides via direct, covalent bonding of the organophosphorus molecule and acetylcholinesterase (AChE). In normal conditions, AChE catalyzes the breakdown of acetylcholine and other cholines that act as neurotransmitters [1]. The mechanism of action of OPs involves phosphorylation of the $-\mathrm{OH}$ residue of serine located in the active site of the enzyme. Early combination of the substances may be reversible. However, over time, the disconnection of selected groups of the complex (partial dealkylation) and the aging process of the enzyme continues.

Address for correspondence: Anna Katarzyna Orzeł, Toxicology Clinic, Medical University, Lublin, Poland.

E-mail: anna.k.orzel@gmail.com

Received: 18.08.2021; accepted: 12.01.2022; first published: 11.02 .2022
During this period, reactivation of acetylcholinesterase both spontaneous and forced by application of specific antidotes (oximes) - is impossible [2]. The intake of an OPs may be through ingestion, inhalation or y dermal exposure [3]. Moreover, a significant part of consumption of an OPs is intentional, i.e. self-poisoning resulting in death by suicide [4].

Every year, around 3 million people are exposed to organophosphates resulting in 300,000 deaths worldwide [5]. In Poland, according to the Narodowy Fundusz Zdrowia (NFZ), the National Health Fund, in 2018 - 2019 alone, 885 people were intoxicated with pesticides of whom 475 required hospitalization [6]. Yet, there are few current researches concerning the prevalence and mortality from OPs poisoning in Poland. This underlines the importance of this study as agriculture is significant branch in Polish economy and such intoxications still occur.

Acetylcholinesterase deficiency causes the accumulation of acetylcholine in the presynaptic cleft and development of 
cholinergic symptoms. The clinical picture of OPs intoxication may be differentiated - from cholinergic toxidrome, intermediate syndrome, OP-induced delayed polyneuropathy to chronic OP-induced neuropsychiatric disorder (OPIDN) [7]. Severe cholinergic crisis manifests by salivation, lacrimation, bronchospasm, bradycardia or myosis. Eventually, the toxidrome leads to respiratory failure, paralysis, seizures and depression of the central nervous system $[8,9]$.

The diagnostic process in poisoning by an OPs is based on the clinical condition of the patient and examination of the serum cholinesterase level. Due to the differentiated symptoms of intoxication, continuous control and early management have to be introduced in the patient's treatment. Typically,the basic step in poisoning by an OPs involves then application of antidotes - antimuscarinic, agent atropine (ATR) and cholinesterase reactivator, pralidoxime (PAM) [10].

\section{OBJECTIVE OF THE STUDY}

The aim of this retrospective cohort study was to present the clinical manifestation and cholinesterase level changes in intoxication with organophosphorus compounds in patients hospitalized in the Department of Cardiology and Toxicology in 2013-2020.

\section{MATERIALS AND METHOD}

A data base was created by analysis of the hospital documents of 34 patients hospitalized in Department of Cardiology and Toxicology in Lublin between 2013 - 2020. Inclusion criterion to the study was diagnosis of intoxication with organophosphates. The components examined in the study included:

- social factors: age, gender, place of residence, suicide attempt, fatal hospitalizations;

- patient state: acute respiratory failure, multi-organ dysfunction syndrome (MODS), cardiac arrest, requirement of mechanical ventilation, alcohol use disorder, comorbidities.

- Way of intoxication - oral or inhalation.

- Laboratory indicators: cholinesterase level, creatinine phosphokinase level (CPK) and presence of alcohol in bloodstream. From obtained levels of cholinesterase, the lowest value was used for the examination (to show the range of enzyme inactivation). On the other hand, for CPK levels, the highest value was processed (to indicate the possibility of muscle injury).

- Application of antitoxins: atropine only application of both - atropine and toxogonin. These components were enlisted in patient epicrisis.

Statistical analysis involved frequency tables with percentage value. Moreover, the non-parametric Chisquare test was used for independent variables. Additionally, application of the parametric t-Student test (with homogeneity of variance Levine test) enabled analysis of the relationships between cholinesterase or creatine phosphokinase levels and examined components. The level of static significance was set to $\mathrm{p}=0.05$. Processing of the data involved calculations using Excel spreadsheets and IBM SPSS Statistics.

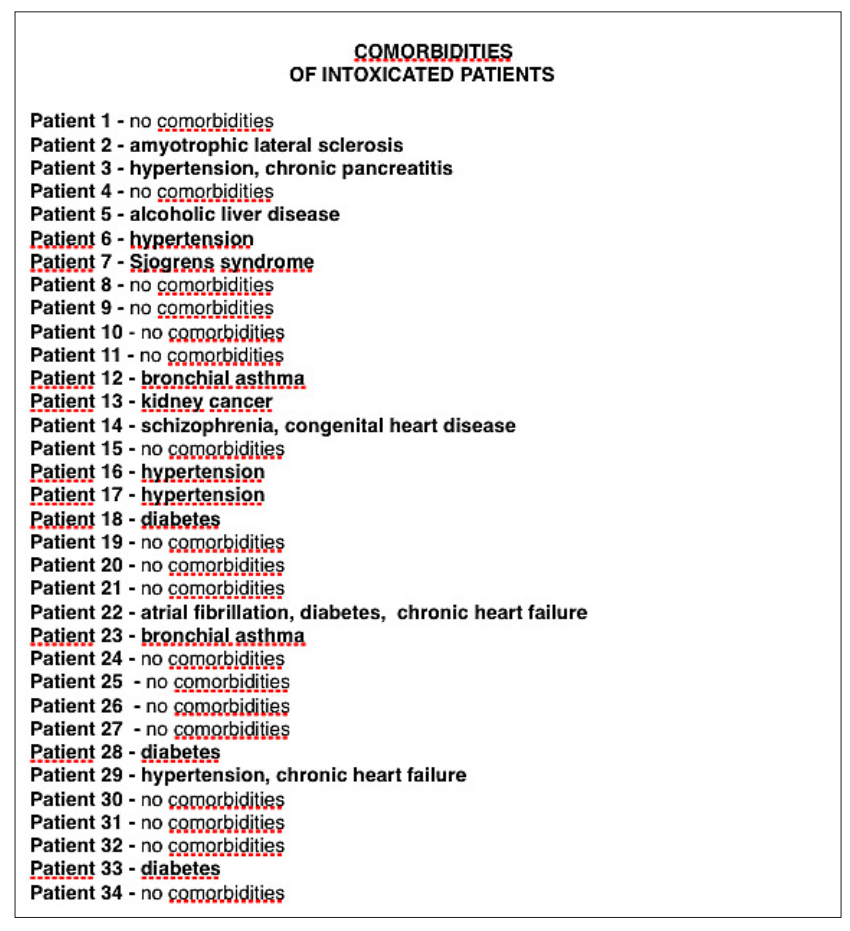

Figure 1. Comorbidities of the patients $(n=34)$

\section{RESULTS}

Data presentation. Data analysis resulted in the admission to the study of 34 patients after intoxication by an OPs (Tab.1). Mean age of the patients -47.0 ; median age -45.5 . The oldest patient was 88 -years-old and the youngest -23 .

Table 1. Patients intoxicated with organophosphates $(n=34)$ with percentage value indicated

\begin{tabular}{|c|c|c|}
\hline Gender & Female & $10(29.4 \%)$ \\
\hline & Male & $24(70.6 \%)$ \\
\hline \multirow[t]{2}{*}{ Place of residence } & City & $1(2.9 \%)$ \\
\hline & Village & $33(97.1 \%)$ \\
\hline \multirow[t]{2}{*}{ Suicidal attempt } & Yes & $10(29.4 \%)$ \\
\hline & No & $24(70.6 \%)$ \\
\hline \multirow[t]{2}{*}{ Result of hospitalization } & Discharged home & $27(79.4 \%)$ \\
\hline & Death & $7(20.6 \%)$ \\
\hline \multirow[t]{4}{*}{$\begin{array}{l}\text { Clinical condition of patient's } \\
\text { intoxicated with organophosphates } \\
\text { (OPs) }\end{array}$} & Acute respiratory failure & $13(38.2 \%)$ \\
\hline & MODS & $8(23.5 \%)$ \\
\hline & Cardiac arrest & $10(29.4 \%)$ \\
\hline & $\begin{array}{l}\text { Requirement of mechanical } \\
\text { ventilation }\end{array}$ & $13(38.2 \%)$ \\
\hline
\end{tabular}

Almost all patients admitted to the study lived in rural areas. Only one patient came from a city, although he had been intoxicated during agricultural work. Based on psychiatric consultations and family testimonies in the epicrisis, it was possible to determine the percentage of patients with deliberate and suicidal poisonings and patients with alcohol use disorder (Tab.1). A severe condition of the patients brought the mortality rate to $20.6 \%$. Considering the clinical manifestation of intoxications with OPs, $38.2 \%$ of 
patients experienced acute respiratory failure, and the same percentage required mechanical ventilation. The number of patients with MODS and cardiac arrest was also presented.

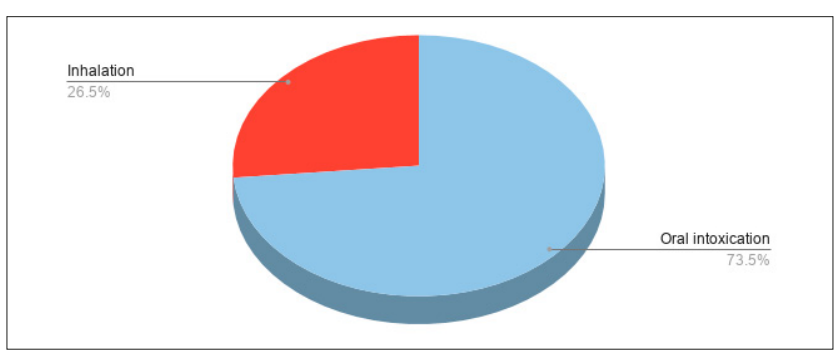

Figure 2. Ways of intoxication with organophosphates (OPs)

Two groups of patients were admitted to the study -9 $(26.5 \%)$ patients were intoxicated via inhalation whereas the majority of patients $-25(73.5 \%)$ poisoned via the oral route (Fig. 2).

Examination of the cholinesterase level was used to determine its inhibition by an OPs, the effect of which was presented in $61.8 \%$ of patients with a reduced level of cholinesterase. Numerical assessment of the cholinoesterase level and its relationship was further examined. Regarding different indicators, the presence of alcohol in plasma and level of creatinine phosphokinase (CPK) was measured. It should be underlined that 6 patients did not have their CPK levels checked (Tab. 2).

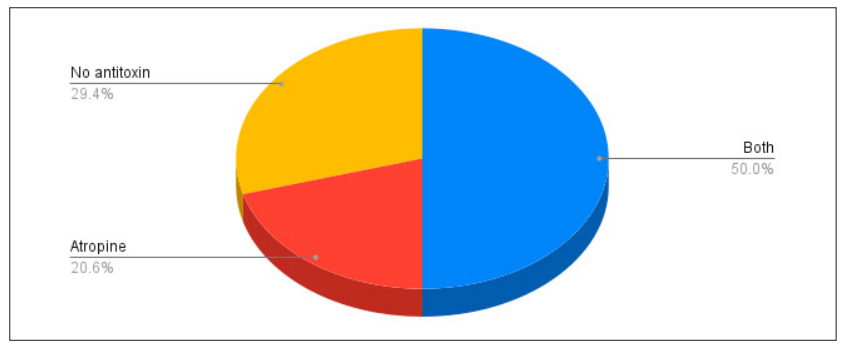

Figure 3. Implementation of antitoxins

The application of antitoxins was differentiated among the patients: 17 (50.0\%) received both medications - atropine and toxogonin, whereas $7(20.6 \%)$ had only atropine administered. $29.4 \%$ of patients were treated without any antitoxin (Fig. 3).

Data processing. The influence of intoxication pathway on cholinesterase level was investigated. It was revealed that patients poisoned via the oral route had a lower level of cholinesterase than patients who were intoxicated through inhalation. The differences were assessed as statistically significant $(\mathrm{p}<0.05)$. A similar pattern was observed while comparing patients with comorbidities with the controlled group, but differences were not statistically significant (Tab. 3).

In order to emphasize the toxic effect of organophosphates (OPs), the relationships between cholinesterase level and varying conditions - acute respiratory failure, MODS, cardiac arrest and mortality rate - were analyzed.

The general pattern indicated that cholinesterase levels were lower in patients with a present condition. For example, patients with cardiac arrest $(n=10)$ had a lower level of cholinesterase $(547.02 \mathrm{U} / \mathrm{l})$ than patients without this complication $(\mathrm{n}=24 ; 4636.25 \mathrm{U} / \mathrm{l})$. The differences were assessed as statistically significant $(\mathrm{p}<0.05)($ Tab. 4).
Table 2. Laboratory indicators in patients intoxicated with organophosphates $(n=34)$

\begin{tabular}{ll}
\hline Acute respiratory failure & $13(38.2 \%)$ \\
\hline MODS & $8(23.5 \%)$ \\
\hline Cardiac arrest & $10(29.4 \%)$ \\
\hline Requirement of mechanical ventilation & $13(38.2 \%)$ \\
\hline Alcohol use disorder & $10(29.4 \%)$ \\
\hline
\end{tabular}

Table 3. Relationship between cholinesterase level and route of intoxication / comorbidities

\begin{tabular}{|c|c|c|c|}
\hline & $0 r=1 n-25$ & Mean value of cholinesterase level (U/I) & \multirow{3}{*}{$\begin{array}{c}\mathrm{p} \\
<0.05\end{array}$} \\
\hline \multirow{2}{*}{$\begin{array}{l}\text { Intoxication } \\
\text { pathway }\end{array}$} & ) & 2258.01 & \\
\hline & $\begin{array}{l}\text { Inhalation } \\
(\mathrm{n}=9)\end{array}$ & 6698.89 & \\
\hline \multirow{2}{*}{ Comorbidities } & $\begin{array}{l}\text { YES } \\
(n=19)\end{array}$ & 2335.37 & \multirow{2}{*}{$\begin{array}{c}p \\
>0.05\end{array}$} \\
\hline & $\begin{array}{l}\text { No } \\
(n=15)\end{array}$ & 4824.55 & \\
\hline
\end{tabular}

Table 4. Relationship between cholinesterase level and patients' condition

\begin{tabular}{|c|c|c|c|}
\hline \multirow{2}{*}{$\begin{array}{l}\text { Acute } \\
\text { respiratory failure }\end{array}$} & YES $(n=13)$ & 993.79 & \multirow{2}{*}{$\begin{array}{c}\mathrm{p} \\
<0.05\end{array}$} \\
\hline & $\mathrm{NO}(\mathrm{n}=21)$ & 4943.86 & \\
\hline \multirow{2}{*}{ Respiratorotherapy } & YES $(n=13)$ & 548.17 & \multirow{2}{*}{$\begin{array}{c}\mathrm{p} \\
<0.05\end{array}$} \\
\hline & $\mathrm{NO}(\mathrm{n}=21)$ & 5219.71 & \\
\hline \multirow{2}{*}{ MODS } & YES $(n=8)$ & 244.13 & \multirow{2}{*}{$\begin{array}{c}\mathrm{p} \\
<0.05\end{array}$} \\
\hline & $\mathrm{NO}(\mathrm{n}=26)$ & 4914.89 & \\
\hline \multirow{2}{*}{ Cardiac arrest } & YES $(n=10)$ & 547.02 & \multirow{2}{*}{$\begin{array}{c}\mathrm{p} \\
<0.05\end{array}$} \\
\hline & $\mathrm{NO}(\mathrm{n}=24)$ & 4636.25 & \\
\hline \multirow{2}{*}{$\begin{array}{l}\text { Fatal } \\
\text { hospitalization }\end{array}$} & YES $(n=7)$ & 265.87 & \multirow{2}{*}{$\begin{array}{c}\mathrm{p} \\
<0.05\end{array}$} \\
\hline & $\mathrm{NO}(\mathrm{n}=27)$ & 4254.78 & \\
\hline
\end{tabular}

Table 5. Relationship between creatinine phosphokinase level and death rate

\begin{tabular}{|c|c|c|c|}
\hline & & Mean value of cholinesterase level (U/l) & \\
\hline \multirow{2}{*}{$\begin{array}{l}\text { Fatal } \\
\text { hospitalization }\end{array}$} & & 265.87 & \multirow{2}{*}{$\begin{array}{c}\mathrm{p} \\
<0.05\end{array}$} \\
\hline & $\mathrm{NO}(\mathrm{n}=27)$ & 4254.78 & \\
\hline
\end{tabular}

Analysis of the connection between the creatinine phosphokinase level and mortality rate revealed that fatal patients had a much higher level of the enzyme (5062.66 $\mathrm{U} / \mathrm{l}$ ), compared to the other group (Tab. 5). No statistical significance was revealed. It should be underlined that a group of 28 patients was included in the mentioned analysis.

The majority of patients admitted to the study required the administration of antitoxin. On the other hand, cholinesterase level was significantly lower in the group with antitoxin application $(\mathrm{p}<0.05)($ Tab. 6$)$.

Table 6. Relationship between cholinesterase level and antitoxin application

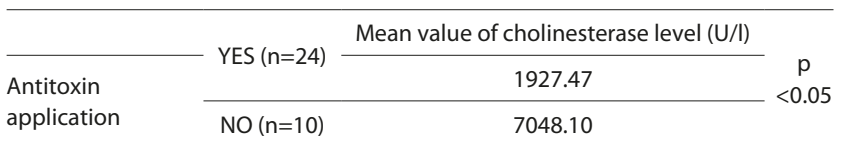

The relationship between fatal hospitalizations and administration of antitoxin revealed no statistical difference. 
Table 7. Relationship between fatal hospitalizations and patients conditio

\begin{tabular}{|c|c|c|c|c|c|c|c|c|c|}
\hline & & \multicolumn{2}{|c|}{ ANTITOXIN } & \multicolumn{2}{|c|}{ COMORBIDITIES } & \multicolumn{2}{|c|}{ RESPIRATOROTHERAPY } & \multicolumn{2}{|c|}{ CARDIAC ARREST } \\
\hline & & NO & YES & NO & YES & NO & YES & NO & YES \\
\hline & Number & 10 & 17 & 11 & 16 & 21 & 0 & 24 & 3 \\
\hline & $\%$ of fatal hospitalizations & $37.0 \%$ & $63.0 \%$ & $40.7 \%$ & $59.3 \%$ & $77.8 \%$ & $0.0 \%$ & $88.9 \%$ & $11.1 \%$ \\
\hline & $\%$ of condition & $100.0 \%$ & $70.8 \%$ & $73.3 \%$ & $84.2 \%$ & $100.0 \%$ & $0 / 0 \%$ & $100.0 \%$ & $30.0 \%$ \\
\hline & Number & 0 & 7 & 4 & 3 & 6 & 7 & 0 & 7 \\
\hline & $\%$ of condition & $0.0 \%$ & $29.2 \%$ & $44.1 \%$ & $55.9 \%$ & $46.2 \%$ & $53.8 \%$ & $0.0 \%$ & $70.0 \%$ \\
\hline $\mathrm{p}$-value & & \multicolumn{2}{|c|}{$p>0.05$} & \multicolumn{2}{|c|}{$p>0.05$} & \multicolumn{2}{|c|}{$\mathrm{p}<0.05$} & \multicolumn{2}{|c|}{$p<0.05$} \\
\hline
\end{tabular}

On the contrary, such difference was observed in association between fatal hospitalizations and need for respiratorotherapy and cardiac arrest $(\mathrm{p}<0.05)($ Tab.7).

Finally, the impact of patients age on mortality was investigated. Although patient who died were older, no statistical differences were observed.

Table 8. Relationship between fatal hospitalizations and age of patients

\begin{tabular}{ccc}
\hline & \multicolumn{1}{c}{$\begin{array}{c}\text { Mean age of the patient in the day } \\
\text { of admission }\end{array}$} & $p$ \\
\cline { 3 - 3 } Fatal hospitalization $(n=7)$ & 52.29 & 0.05 \\
\cline { 2 - 3 } & NO $(n=27)$ & 45.59 \\
\hline
\end{tabular}

\section{DISCUSSION}

According to studies, intoxication with OPs contributes to a higher mortality rate than in cases of other acute chemical poisoning [1]. The problem of OPs toxicity particularly affects people from rural regions related with agriculture; hence the conducted research concerned patients from agricultural areas who had been exposed to OPs poisoning due to their profession as a farmer. It is known that the course of a poisoning by an OPs may be diverse. The presented study shows that the mortality in OPs poisoning was related to the level of cholinesterase. The concentration of this enzyme was significantly lower in fatal hospitalization compared to the discharged patientsThe current study is in line with a report by Sanjay et al., who confirmed the relationship between changes in cholinesterase levels and the severity of intoxication by an OPs. The mentioned study presented that the enzyme level was significantly lower in patients with severe intoxication than in cases of mild and moderate toxicity [11]. On the other hand, Aygun et al, supported the examination of cholinesterase in diagnosis of acute OPs intoxication, and rejected its role as a possible indicator of intoxication severity [12].

The toxicity of an OPC depends on various factor, including the type of the agent, dose, time duration of exposure, as well as the route of intoxication [13]. In the current study, most of the patients had been poisoned through the oral route. Statistical analysis revealed that the oral intake of an OPs decreased cholinesterase concentration to a lower level rather than in case of inhalation. Moreover, in a group of patients with suicidal intentions, all intoxications occurred throthe oral route. Voluntary ingestion of toxic pesticides remains a huge problem in rural areas. According to studies, although proportional mortality due to suicide was lower in farm workers than in non-farm workers, completed suicide rates were 2.25 times higher for people working in agriculture. Among the possible causes, regular access to pesticides including toxic OPs play an important role [14]. In the current study, one of the patients hospitalized due to poisoning by an OPs, was re-admitted a year later after suicide poisoning with a solvent. Sanjay et al, indicated that patients who ingested an OPs with suicidal intentions involved a higher proportion of cases requiring respirator-therapy than in cases of accidental dermal exposure. Such consequences may derive from an increased dose during voluntary oral intake [11].

In the current study, alcohol use disorder (AUD) was recognized as an additional risk factor. Moreover, patients' epicrisis revealed that $1 / 3$ of patients had an elevated level of alcohol in blood. This finding is in agreement with Lee et al. who investigated the association between alcohol consumption and the death rate after OPs poisoning. They proved that a higher blood alcohol concentration $(>173 \mathrm{mg}$ / $\mathrm{dL}$ ) resulted in a three - to fourfold higher risk of 6-month mortality. A higher alcohol concentration may enhance the CNS depression caused by OPs, and eventually lead to respiratory failure [15].

In the presented study, a number of patients were also diagnosed with various comorbidities at the time of intoxication, the most common being hypertension and diabetes. In the vast majority of cases, comorbidities did not significantly affect the course of hospitalization. There was also no statistical difference in cholinesterase level between the control group and patients with comorbidities. Examples of comorbidities were a patient with bronchial asthma and a patient with Sjogrens syndrome, both of whom were intoxicated through inhalation, but due to a relatively low exposure and working outside, the course of poisoning was mild. A comorbidity influenced the course of treatment only in the case of one patient with amyotrophic lateral sclerosis (ALS), whereas a patient who developed severe respiratory failure after deliberate oral exposure to plant protection products, had to be mechanically ventilated by non-invasive methods. In this case, the initial changes and the initial respiratory muscle failure could have contributed to the more severe course of intoxication. Severity of the course of intoxication was related to the amount of the OPs ingested, the dramatic decrease in cholinesterase activity, and consequent clinical symptoms associated with poisoning.

The clinical picture of intoxication by OPs results from stimulation of the muscarinic and nicotinic receptors. Emerging symptoms, commonly described by the acronym DUMBBBELS - defecation, urination, miosis, bradycardia, bronchorrhea, bronchospasm, emesis, lacrimation, and 
salivation - are consequences of muscarinic activity. Stimulation of nicotinic receptors leads to muscular weakness or paralysis, tachycardia and mydriasis [13].

The current study examined the frequency of acute respiratory failure and subsequent consequences of pulmonary tract alterations. It was observed that $38.2 \%$ of experienced acute respiratory failure and the same percentage required mechanical ventilation. Furthermore, there was a statically significant difference in the mean value of cholinesterase serum level. Patients with acute respiratory failure exhibited a lower enzyme level compared to the remaining patients. A similar relationship was detected in patients who, with a decreased level of cholinesterase, required respirator-therapy.

The need for intubation and mechanical ventilation in OPs intoxication can be explained by the stimulation of nicotinic receptors as it leads to obstruction of the respiratory tract and paralysis of the diaphragm [16]. Secondly, in the group of patients who required mechanical ventilation, almost half of them died, whereas in the group of other patients, no deaths occurred. In a study by of Patil et al., 22.22\% of mechanically ventilated patients died; however, in both studies the sample sizes were limited. The authors did not indicate mechanical ventilation as an independent risk factor, but underlined that OPs mortality was the result of overlapping factors and was proportional to age, duration of mechanical ventilation and severity of the OPs poisoning [17].

In 1995, during terrorist attacks in the Tokyo subway, the use a potent OPs - sarin (GB, O-isopropyl methylphosphonofluoridate) resulted in 5,500 exposures and 12 deaths. Apart from previously mentioned clinical symptoms, some victims suffered cardiac arrest [18]. Cardiac complications in OPs intoxications concern nearly twothirds of patients and involve 3 phases [19]: 1) patients undergo a sympathetic phase that manifests itself as sinus tachycardia, 2) parasympathetic discharge with hypoxemia and atrioventricular block of various degrees, 3) conduction disturbances may lead eventually to ventricular fibrillation or pleomorphic ventricular tachycardia (Torsade de Pointes) [20]. In the current study, the majority of cardiac arrest cases had fatal consequences, and no deaths occurred without cardiac arrest.

The current study revealed that there was significant difference in cholinesterase level between patients with and without cardiac complications. Individuals who experienced cardiac arrest had a lower level of cholinesterase than the other patients. The importance of cholinesterase changes was also observed by Shiba et al, as its low serum levels were associated with congestive findings in echocardiography, elevated BNP levels, and higher risk of all-cause death in patients with acute heart failure [21].

It is known that the OPs poisoning leads to the dysfunction of multiple systems within the organism. The analysis reported that $23.5 \%$ patients were classified with MODS. In OPs poisoning, the components of multi-organs dysfunction may be differentiated and involve cardiac collapse, depression of CNS, acute respiratory failure, or neuromuscular weakness. Additionally, a case report by Gunasena and De Silva presented a patient with rhabdomyolysis-induced acute kidney injury (AKI) as a consequence of organophosphate toxicity. The patomechanism of renal complications remains unclea, but possible implications are crystalluria or acute tubular necrosis [22]. The current study showed that the mean cholinesterase level in a group of patients with MODS was a statistically lower than in the other group of patients. Apart from cholinesterase serum levels, the selected patients had their creatinine phosphokinase $(\mathrm{CPK})$ value examin and it appeared that half of them had an increased concentration of the parameter. A high value of $\mathrm{CPK}$ is a reflection of muscle injury due to anticholinesterase-induced myonecrosis, a consequence of muscle hyperactivity at neuromuscular junctions [23]. Furthermore, in cases of fatal hospitalizations, CPK levels were higher (5062.66 U/l) than in the other group (1020.19 U/1), although the differences were not statistically significant. On the other hand, in both groups the values were above the normal range for both genders, which accounted for the general pattern of CPK increase in OPs poisoning. This positive correlation was observed in an article by Kumar et al. in which they indicated that the increase of CPK was related to the severity of OPs poisoning. Elevated levels of CPK were also observed in patients with intermediate syndrome, i.e. a syndrome characterized by muscular weakness, especially of the respiratory muscles and proximal limbs muscles. High levels of CPK contributed to a period of intermediate syndrome with significantly increased values after 48 hours [24].

In the treatment of patients with OPs poisoning, the first stage of therapy should rely on the implementation of muscarinic antagonists atropine and an oxime to restore OP-inhibited AChE. Additionally, research of BalaliMood and Saber underlined the role of benzodiazepines in the prevention of central nervous system seizures [25]. Recommended doses of atropine, in the beginning: $1 \mathrm{mg}$ in adults and $0.01-0.04 \mathrm{mg} / \mathrm{kg}$ in children every 5 minutes until pulmonary secretion ceases. Subsequent doses should be continuously decreased until complete healing is achieved [16]. In the case of obidoxime (toxogonin), Eyer et al. reported that patient poisoned with an OPs responded to $250 \mathrm{mg}$ bolus of obidoxime, followed by continuous infusion at $750 \mathrm{mg} /$ day up to 1 week. After that period, cholinesterase levels should be increased, until no active toxin was present in the organism [26]. In the current study, the majority of patients required antidotal treatment with atropine and toxogonin, and atropine only, whereas $1 / 3$ of patients had no antidotal treatment introduced.

While investigating the relationship between antidotal treatment and mortality, it was observed that in the group of patients administered with antitoxin, $29.2 \%$ of hospitalizations were fatal and $70.8 \%$ of patients were discharged home. Moreover, all fatal hospitalization in the study were in group of patients administered with antitoxin. This data may indicate the severity of the poisoning in the group of patients with antidotal treatment.

\section{CONCLUSION}

The management of patients with organophosphate poisoning remains challenging and requires continuous control by the medical staff. A significant step in the diagnostic process is assessment of the cholinesterase level. The study revealed that a significant decrease in enzyme level adversely correlates with an increase in mortality rate. Moreover, lower values of cholinesterase level were observed in patients with acute respiratory failure, MODS, cardiac arrest, and in the group that required mechanical ventilation. Additionally, the route of OPs intake remains an important indicator because 
patients who ingested an OPs had a significantly lower level of cholinesterase than patients who inhalated an OPs.

Early diagnosis of the intoxication enables physicians to introduce antidotal treatment, including atropine and oximes, in the first steps of the therapy, which prevents the development of cholinergic syndrome and future consequences. Nevertheless, organophosphates (OPs) remains an especially important issue in rural-based regions. People working in agriculture are not only exposed to occupational poisoning due to non-compliance with the rules of occupational health and safety, but also have easier access to such substances in suicidal attempts.

\section{REFERENCES}

1. Hoffman RS, Howland MA, Lewin NA, et al. Goldfrank's Toxicologic Emergencies, Insectidices: organic phosphorous compounds and carbamates, 2019: 1409-1420.

2. Pach J. Zarys toksykologii klinicznej. 2009: 496-501.

3. Suratman S, Edwards JW, Babina K. Organophosphate pesticides exposure among farmworkers: pathways and risk of adverse health effects. Rev Environ Health. 2015; 30(1): 65-79. https://doi.org/10.1515/ reveh-2014-0072

4. Raveendra K R, Mohan C N, Nandan Kodur. A study to assess the utility of peradeniya organophosphorous poisoning (POP) scale, poisoning severity score (PSS) and glasgow coma scale (GCS) in predicting severity and treatment outcome in acute organophosphorous poisoning. International J Contemp Med Res. 2020; 7(2): B20-B24. https://doi. org/10.21276/ijcmr.2020.7.2.22

5. Robb EL, Baker MB. Organophosphate Toxicity. [Updated 2020 Jul 27]. In: StatPearls [Internet]. Treasure Island (FL): StatPearls Publishing; 2021 Jan-. Available from: https://www.ncbi.nlm.nih.gov/books/ NBK470430/

6. Sprawozdanie z realizacji w latach 2018-2019 krajowego planu działania na rzecz ograniczenia ryzyka związanego ze stosowaniem środków ochrony roślin na lata 2018-2022, https://www.gov.pl/web/rolnictwo/ krajowy-plan-dzialania-na-rzecz-ograniczenia-ryzyka-zwiazanego-zestosowaniem-srodkow-ochrony-roslin (accessed: 27.10.2020).

7. Petreski T, Kit B, Strnad M, Grenc D, Svenšek F. Cholinergic syndrome: a case report of acute organophosphate and carbamate poisoning. Arh Hig Rada Toksikol. 2020; 71(2): 163-166. https://doi.org/10.2478/ aiht-2020-71-3413

8. Jokanović M. Neurotoxic effects of organophosphorus pesticides and possible association with neurodegenerative diseases in man: A review. Toxicology. 2018; 410: 125-131. https://doi.org/10.1016/j.tox.2018.09.009

9. Lott EL, Jones EB. Cholinergic Toxicity. [Updated 2021 May 19]. In: StatPearls [Internet]. Treasure Island (FL): StatPearls Publishing; 2021 Jan-. Available from: https://www.ncbi.nlm.nih.gov/books/ NBK539783/

10. Reddy BS, Skaria TG, Polepalli S, et al. Factors associated with outcomes in organophosphate and carbamate poisoning: a retrospective study. Toxicol Res. 2020; 36(3): 257-266. https://doi.org/10.1007/s43188-01900029-X
11. Sanjay A, Siddheshwar V, Sheshrao S. The Clinico-Demographic Study of Morbidity and Mortality in Patients with Organophosphate Compound Poisoning at Tertiary Care Hospital in Rural India. Int J Adv Med. 2017; 4: 809-818. https://doi.org/10.18203/2349-3933. ijam 20172277

12. Aygun D, Doganay Z, Altintop L, et al. Serum acetylcholinesterase and prognosis of acute organophosphate poisoning. J Toxicol Clin Toxicol. 2002; 40(7): 903-910. https://doi.org/10.1081/clt-120016962

13. King AM, Aaron CK. Organophosphate and carbamate poisoning. Emerg Med Clin North Am. 2015; 33(1): 133-151. https://doi. org/10.1016/j.emc.2014.09.010

14. London L, Flisher AJ, Wesseling C, Mergler D, Kromhout H. Suicide and exposure to organophosphate insecticides: cause or effect? Am J Ind Med. 2005; 47(4): 308-321. https://doi.org/10.1002/ajim.20147

15. Lee YH, Oh YT, Lee WW, et al. The association of alcohol consumption with patient survival after organophosphate poisoning: a multicenter retrospective study. Intern Emerg Med. 2017; 12(4): 519-526. https:// doi.org/10.1007/s11739-016-1484-9

16. Karakus A, Celik MM, Karcioglu M, Tuzcu K, Erden ES, Zeren C. Cases of organophosphate poisoning treated with high-dose of atropine in an intensive care unit and the novel treatment approaches. Toxicol Ind Health. 2014; 30(5): 421-425. https://doi.org/10.1177/0748233712462478

17. Patil G, Murthy N, Nikhil M. Contributing Factors for Morbidity and Mortality in Patients with Organophosphate Poisoning on Mechanical Ventilation: A Retrospective Study in a Teaching Hospital. J Clin Diagn Res. 2016; 10(12): UC18-UC20. https://doi.org/10.7860/ JCDR/2016/22116.9038

18. Abou-Donia MB, Siracuse B, Gupta N, Sobel Sokol A. Sarin (GB, O-isopropyl methylphosphonofluoridate) neurotoxicity: critical review. Crit Rev Toxicol. 2016; 46(10): 845-875. https://doi.org/10.1080/1040 8444.2016.1220916

19. Peter JV, Sudarsan TI, Moran JL. Clinical features of organophosphate poisoning: A review of different classification systems and approaches. Indian J Crit Care Med. 2014; 18(11): 735-745. https:// doi.org/10.4103/0972-5229.144017

20. Cha YS, Kim H, Go J, et al. Features of myocardial injury in severe organophosphate poisoning. Clin Toxicol (Phila). 2014; 52(8): 873-879. https://doi.org/10.3109/15563650.2014.944976

21. Shiba M, Kato T, Morimoto T, et al. Serum cholinesterase as a prognostic biomarker for acute heart failure. Eur Heart J Acute Cardiovasc Care. 2021; 10(3): 335-342. https://doi.org/10.1093/ehjacc/zuaa043

22. Gunasena JB, De Silva ST. Organophosphate Poisoning Complicated by Rhabdomyolysis-Induced Acute Kidney Injury: A Case Report and Review of Literature. J Clin Toxicol. 2020; 10(5): 1000450. https://dx.doi. org/10.35248/2161-0495.20.10.450

23. John M, Oommen A, Zachariah A. Muscle injury in organophosphorous poisoning and its role in the development of intermediate syndrome. Neurotoxicology. 2003; 24(1): 43-53. https://doi.org/10.1016/s0161$813 x(02) 00111-0$

24. Kumar GC, Bhuvana K, Venkatarathnamma PN, Sarala N. Serum creatine phosphokinase as predictor of intermediate syndrome in organophosphorus poisoning. Indian J Crit Care Med. 2015; 19(7): 384-387. https://doi.org/10.4103/0972-5229.160274

25. Balali-Mood M, Saber H. Recent advances in the treatment of organophosphorous poisonings. Iran J Med Sci. 2012; 37(2): 74-91.

26. Eyer F, Worek F, Eyer P, et al. Obidoxime in acute organophosphate poisoning: 1 - clinical effectiveness. Clin Toxicol (Phila). 2009; 47(8): 798-806. https://doi.org/10.1080/15563650903206828 